\title{
A CLINICAL STUDY OF THE INTERNAL FIT OF ZIRCONIA AND GOLD PLATINUM CAD/CAM FRAMEWORKS FIXED DENTAL PROSTHESIS
}

\author{
Sahar Abdel Wahab* and Ahmed M.Hamdy**
}

\begin{abstract}
Statement of problem: A new CAD/CAM technology for the fabrication of metal copings for metal-ceramic restorations has been introduced. However, no sufficient data on the internal fit of metal- ceramic restorations produced by this method is available yet.

Purpose: This study was performed to compare the internal gap between abutment teeth and posterior fixed dental prosthesis (FDPs) fabricated utilizing yttria-stabilized tetragonal zirconia polycrystals and Gold Platinum metal ceramic alloy frameworks.

Materials and Methods: A randomized controlled clinical trial was performed, twenty FPDs were fabricated with yttria -stabilized zirconia poly crystals (Y-TZP -IPS e.max zir CAD) and metal -ceramic (MC Au-Pt) as follow(n=10): thirty patients were randomly selected for internal fit measurements. The internal fit of the FPDs frameworks were measured using replica technique. Data was analyzed with (ANOVA) test, followed by Tukey's post hoc test.
\end{abstract}

Results: The internal gap, according to the thickness of the replica, was measured under magnification at the following locations: cervical, axial, and occlusal (cusp-tips and central). The internal gaps of FPDs with zirconia frameworks were significantly larger in cervical, axial, and centro-occlusal regions (cervical: $69.549 \pm 10.484 \mu \mathrm{m}$ vs. $60.493 \pm 15.940 \mu \mathrm{m}$ axial : $75.678 \pm$ $8.996 \mu \mathrm{m}$ vs. $53.356 \pm 12.916 \mu \mathrm{m}$; and centro-occlusal: $78.159 \pm 10.272 \mu \mathrm{m}$ vs. $69.343 \pm 4.446$ $\mu \mathrm{m})$. The cervical gaps next to the pontics were significantly larger compared with those of the outer walls in both types of FPDs (zirconia: mean difference $71.655 \pm 4.583 \mu \mathrm{m}$; metal-ceramic: mean difference $52.891 \pm 5.665 \mu \mathrm{m})$.

Conclusion: Posterior three-unit FPDs milled zirconia frameworks fabricated according to the manufacturer's specifications exhibited larger internal gaps than those constructed using milled Gold Platinum metal-ceramic technique.

Clinical implications: Both milled Gold platinum metal ceramic, and zirconia may be an alternative for 3- unit frameworks in terms of internal fit. Zirconia showed inferior results but within the range of clinical acceptability.

KEY WORDS: adaptation; fixed partial dentures; internal fit; replica technique; zirconia.

\footnotetext{
*Associate Professor , Fixed Prosthodontics Department , Faculty Of Dental Medicine For Girls Al-Azhar University.

** Associate professor, Fixed Prosthodontics Department, Faculty of Dentistry, MSA University.
} 


\section{INTRODUCTION}

Metal ceramics are still the most widely used material for fabricating crowns and FPDs ${ }^{1}$. The traditional technique for fabricating the metal substructure is the lost-wax technique and using different metal alloys for casting. Recently a new CAD/CAM technology (BEGO Medifacturingsystem, BEGO Medical, Germany) for the fabrication of metal copings for metal-ceramic crowns has been introduced ${ }^{2}$. However, no sufficient data on the internal fit of metal-ceramic crowns produced by this method is available yet.

The CAD/CAM technique employs sophisticated technologies, and the core can be fabricated from densely sintered or partially-sintered ceramic blocks. A scanner digitalizes the prepared tooth, and the framework or a restoration is then fabricated according to the previously established design. Additionally, CAD/ CAM systems have been developed to eliminate or minimize potential sources of errors present in conventional manufacturing techniques ${ }^{2}$.

Recently, the high-strength ceramic zirconia was introduced for dental application. Based on their excellent physical properties, zirconia has been advocated as framework material for all-ceramic FPDs ${ }^{3,4}$.

The physical properties of densely sintered zirconia, however, make the grinding procedures difficult, time consuming and leading to high wear of milling instruments ${ }^{5-7}$. In order to eliminate these technical difficulties, an alternative technique for manufacturing zirconia was developed. This technique allows the frameworks to be ground out of zirconia in the pre sintered, soft stage. The pre sintered frameworks, however, have to be sintered to full density in order to reach optimal material properties. This sintering procedure was accompanied with high sintering shrinkage of zirconia of about $2.2 \%$. In order to compensate for the shrinkage, the size of the milled, pre sintered frameworks has to be larger by this difference ${ }^{8,9}$. Hence, to compensate for this sintering shrinkage, new computer software had to be developed.

Considering that most of the previous investigations did not separate the internal fit into different regions (occlusal and axial spaces) ${ }^{10}$ and the small number of studies comparing the internal fit of all-ceramic systems to that of metal-ceramic, we sought to examine the in internal fit (cervical, axial, occlusal, and total mean) of a posterior allceramic FPDs . Two null hypotheses were tested: 1- there were no differences between cervical, axial, occlusal and total mean measurements within each group; 2- there were no differences in internal fit between the two groups.

\section{MATERIALS AND METHODS}

Twenty FPDs were selected for evaluation of the fit between abutment teeth and frameworks under clinical condition in twenty patients (nine women and eleven men). The study was approved by the ethical committee of Al-Azhar University Girls branch, Egypt.

These patients were part of a randomized controlled clinical trial of 50 subjects who had given informed consent to participate, and in whom 30 zirconia ceramic and 20 metal-ceramic posterior FPDs frameworks were evaluated. The 20 patients included in the analysis of FPD adaptation were randomly selected by the statistician according to the patient list of the randomized controlled clinical trial. The test group consisted of 10 FPDs with zirconia frameworks (Y-TZP -IPS e.max zir Cercon; Degu Dent), and 10 metal-ceramic (MC Au $\mathrm{Pt})$ FPDs .

For each tooth an impression was made using heavy body polyvinyl siloxane impression material (Imprint 3M ESPA),which was sectioned and used as an anatomical guide during tooth reduction. The abutment teeth were prepared in both groups following the principles for metal-ceramic 
restorations ${ }^{11}$, modified according to the needs of all-ceramic restorations ${ }^{3}$.Modification of the preparation include a marginal shoulder preparation, the tapering of the axial walls by $6-10^{\circ}$, and the meticulous rounding of all edges. The preparations were performed by first author.

Impressions were made with polyether material (Permadyne, 3M Espe, Germany) and poured $1 \mathrm{~h}$ after setting. The master model was cast in die stone type 4 (Fujirock, GC Europe, Belgium). The materials were used according to the manufactures instructions. The computer aided design (CAD) was performed by in-lab extra oral scanner "in Eos" (Sirona Dental Systems GmbH, D-64625 Bensheim, Germany).

Zirconia and metal copings were designed with the CAD software. The die spacer was selected according to manufacturers instructions. Two layers in zirconia and one layer in Cobalt chromium. Zirconia(Y-TZP -IPS e.max zir CAD) and Gold platinum (Au-Pt)(Au 87, Pt 10.6, Zn 1.5, In 0.3, Rh 0.2, Ta 0.2, Mn 0.2; Bio PontoStar, BEGO Medical) frameworks were fabricated by milling (DeguDent GmbH, Rodenbacher Chaussee 463457 Hanau Wolfgang Germany).

The type and size of the zirconia blocks were selected as (Cercon smart ceramics). The frameworks were milled with a high speed 5-axis simultaneous motion, the connectors were milled with a width of $2.5 \mathrm{~mm}$ and a height of $5 \mathrm{~mm}$ between the premolar and first molar and with a height of $4 \mathrm{~mm}$ between first and second molars, then sintered in the HT furnace (high-Temperature Furnace with program Control Unit) according to the manufacturer instructions (MiHM-Vogt GMBH\&CO.KG .Dental Geratebau. Germany). As zirconia blocks were semi sintered, the $\mathrm{CAD} / \mathrm{CAM}$ machine is programmed to produce an enlarged restoration with $1.253 \%$ which is equal to the amount of shrinkage percent expected during sintering process.
Ten frameworks were fabricated from $\mathrm{Au}-\mathrm{Pt}$ blocks. The same design made by the in-lab extra oral scanner "inEos" was used. All frameworks were simultaneously milled.

After adaptation of frameworks onto the master casts, a clinical try-in of all frameworks was performed by one operator. It was performed by using a dental probe with a fine tip (EPD5658XTS; HU-Friedy, Lonay, Switzerland). The margins were judged according to previous study ${ }^{10}$ as acceptable if no crevice was present or if the margins were probable but the probe did not penetrate a gap. If a gap was present, the internal clinical adaptation was clinically checked using a silicone material (Black Fit Checker; GC Europe, Wa“ ngi, Switzerland). Interferences were removed with a diamond bur under constant water cooling until an acceptable marginal adaptation was achieved.

After the clinical try-in, both zirconia frameworks and metal frameworks were veneered. The internal fit of the FPDs was registered by utilizing a replica technique ${ }^{10}$ during the bisque-stage ceramic tryin. The bisque-stage was chosen for adaptation analysis, All remnants of the silicone material were eliminated during the final veneer firing, thus minimizing any reduction in the adhesive strength of the resin luting cement. As the marginal areas were improved with further application of shoulder porcelain after the bisque-stage try-in, only the cervical adaptation of the framework to the inner side of the shoulder was measured.

The internal fit of two groups were analyzed by replica technique. This analysis was performed by the same operator who had performed the clinical try-in. Any interferences will be removed from bisque stage FPDs until acceptable marginal adaptation.

The internal surfaces were cleaned with $70 \%$ alcohol and then dried with air to remove debris. The FPDs were filled with a light body silicone impression material (Express; 3M ESPE) and seated 
on the abutments of the master cast with finger pressure. After setting, the impression material adhering to the internal side of the frameworks was removed together with the FPDs. This thin layer was stabilized by placing a heavy body silicone material (Express; 3M ESPE) of different color into the frameworks.

After setting, both silicone materials were jointly removed from the frameworks. The replicas of the mesial and the distal abutment tooth of each FPD were separately embedded into a custom made epoxy cylinders (Epofix; Streuers) with central groove. To standardize the axial cutting, two grooves were made in the cylinder walls mesial and distal to central groove act as guidance. The replicas were fixed on metal pins along the long axis of the abutment. The cylinders were filled with a clear silicone material (Memosil; Heraeus Kulzer) (embedded technique). The samples were cut axially with a saw razor blade in bucco-lingual direction resulting in two faces to be measured. Measurements were obtained for cervical surface (CS), axial surface(AS), and occlusal surface(OS) to better evaluate the results in addition to pontic space (PS) and the total mean (TM). Nine different points of each slice were measured: 2 occlusal, 1central, 4 axial (buccal and palatal) and 2 cervical. six faces for nine points of each, resulting in 54 measurements for each crown.

A stereomicroscope (DP10, Olympus, Japan) was used to measure the cement thickness light body and all measurements were performed by the same examiner.

\section{Statistical analysis :}

The mean measurements were analyzed separately according to surfaces from which they were obtained (CS, AS, OS, PS and TM) using oneway ANOVA with Tukey's multiple comparison test at a significance level of $\mathrm{p}<0.05$.

\section{RESULTS}

Within the 10 zirconia FPDs frameworks, one replaced the first premolar, four replaced the second premolar, and five replaced molars. The abutment teeth supporting these frameworks were 1 canine, 10 premolars, and 9 molars. Six of the 10 FPDs with gold-alloy frameworks replaced the second premolar, and 4 replaced molars. Similarly to the previous group, the abutment teeth supporting goldalloy frameworks were 10 premolars, and 10 molars.

TABLE (1) Comparison of the mean gaps and standard deviations (SD) of the zirconia and the metal-ceramic groups for the different measurement locations [cervical surface (CS), axial surface (AS), occlusal surface (OS), pontic surface (PS)and total mean $(\mathrm{TM})]$.

\begin{tabular}{|c|c|c|c|c|c|c|}
\hline & & Mean & $\begin{array}{c}\text { Std. } \\
\text { Deviation }\end{array}$ & $\begin{array}{l}\text { Std.Error } \\
\text { Mean }\end{array}$ & t-value & P-value \\
\hline \multirow[b]{2}{*}{ CS } & $\mathrm{Au}-\mathrm{Pt}$ & 60.493 & 15.940 & 2.008 & & \multirow[b]{2}{*}{0.000} \\
\hline & Y-TZP & 69.549 & 10.484 & 1.320 & 3.715 & \\
\hline \multirow[b]{2}{*}{ AS } & $\mathrm{Au}-\mathrm{Pt}$ & 53.356 & 12.916 & 4.882 & & \multirow[b]{2}{*}{0.000} \\
\hline & Y-TZP & 75.678 & 8.996 & 3.400 & 4.191 & \\
\hline \multirow[b]{2}{*}{ OS } & $\mathrm{Au}-\mathrm{Pt}$ & 69.343 & 4.446 & 1.680 & & \multirow[b]{2}{*}{0.000} \\
\hline & Y-TZP & 78.159 & 10.272 & 3.885 & -1.661 & \\
\hline \multirow[b]{2}{*}{ PS } & $\mathrm{Au}-\mathrm{Pt}$ & 52.891 & 5.665 & 2.139 & & \multirow[b]{2}{*}{0.000} \\
\hline & Y-TZP & 71.655 & 4.583 & 1.732 & 14.394 & \\
\hline \multirow[b]{2}{*}{ TM } & $\mathrm{Au}-\mathrm{Pt}$ & 27.105 & 7.524 & 6.703 & & \multirow[b]{2}{*}{0.000} \\
\hline & Y-TZP & 65.021 & 14.167 & 1.262 & 30.892 & \\
\hline
\end{tabular}

* Comparison was performed without consideration of the different die spacer thicknesses.

Milled gold-alloy frameworks for metalceramic FPDs exhibited smaller internal gaps than milled zirconia frameworks. The total mean of the gaps recorded for the metal frameworks were significantly smaller with total mean values and SD of $27.10 \pm 7.52$ compared with the gaps of zirconia frameworks with mean values and SD of $65.02 \pm$ $14.16(t=30.892 . \mathrm{P}=0.000<0.05)$ (Table 1 , Fig. 1$)$. 


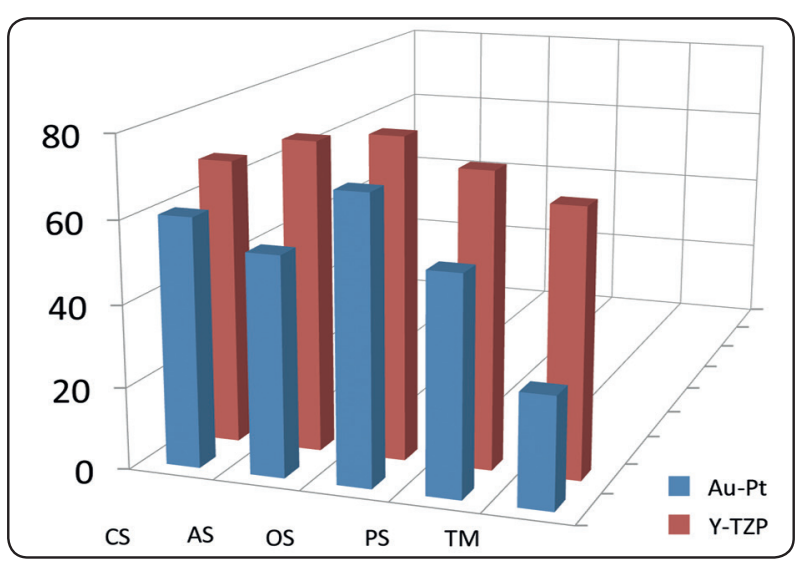

Fig.(1):Comparison of mean gaps of Zirconia and metal ceramic (Gold platinum) groups for the different measurements locations. CS (cervical surface), AS (axial surface), OS (occlusal surface), PS (pontic surface), TM (total mean)

In the cervical area, gaps recorded for the metal frameworks were significantly smaller with mean values and SD of $60.49 \pm 15.94$ compared with the gaps of zirconia frameworks with mean values and SD of $69.54 \pm 10.48(\mathrm{t}=3.715, \mathrm{P}=0.000<0.05)$ (Table 1, Fig. 1).

Similarly, a significant difference was found in the axial and occlusal gaps (axial: metal 53.35 \pm 12.91 , zirconia $75.67 \pm 8.99 .(\mathrm{t}=4.191, \mathrm{p}<0.05)$. While the occlusal gap of metal $69.43 \pm 4.44$, and zirconia $78.15 \pm 10.27(\mathrm{t}=1.661, \mathrm{p}<0.05)$.

By contrast, no significant differences were found for measurements in the occlusal area of the cusp tips. Furthermore, in the occlusal area of both framework materials a significant difference was found between the measurement locations occlusal and central $(\mathrm{P}<0.05)$.

In addition, the gaps between the frameworks and the abutments in the areas facing the pontics and the areas facing away the pontic from the gaps within the same frameworks were compared (including cervical and axial regions). The mean difference of the two areas was calculated by subtracting the gaps facing away from the pontic from the gaps facing the pontic within the same framework. In zirconia group, the adaptation of the areas facing away from the pontics was significantly better than of the areas facing towards the pontics (mean values and SD were $52.89 \pm 5.66$ for metal and $71.65 \pm 4.58, \mathrm{t}=14.39, \mathrm{p}<0.05$ for zirconia).

\section{DISCUSSION}

In this clinical study of the internal gaps of milled zirconia and gold-alloy FPD frameworks, fabricated according to the manufacturers' specifications, significant differences of the two framework types were found. Zirconia frameworks exhibited larger internal gaps, with significantly higher values at cervical, axial, and occlusal measurement locations and total mean. Therefore, the null hypothesis could not be confirmed.

These results are in agreement with the results of other studies dealing with the internal adaptation of computer designed ceramic restorations. ${ }^{11,12}$ Furthermore, the internal gap of the metal frameworks was within the range of clinical data previously published for metal frameworks..$^{14}$ However, the values of gap size in various studies dealing with adaptation of restoration can only be compared to a limited extent due to differences in measurement locations .

One further difficulty for the comparison of study outcomes is the variability of the definition of fit. Fit may be related to the vertical marginal discrepancy and horizontal marginal discrepancy. ${ }^{15}$ However, fit can also be defined as seating discrepancy or internal discrepancy between a restoration and the abutment tooth representing as internal gap.$^{15}$ In the present investigation the fit was analyzed by measuring the internal gaps of the frameworks.

In the present study, both the metal and zirconia frameworks were horizontally reduced to the inner one-third of the shoulder preparation, the measurement of the adaptation of the framework was limited to the internal cervical regions. A tendency for the zirconia frameworks to exhibit larger internal gaps is evident. 
Despite the similarity in the different CAD/ CAM systems in fabricating zirconia restorations, there are differences in the fabrication process, mainly internal space provision, that have been considered by several investigators as a cause of the variation.${ }^{16-18}$ In addition, there is a difference in the experimental procedure that is expected to cause more variation in the outcome at the try-in stage.

The marginal fit of dental restorations is one of the most important criteria when evaluating the clinical acceptability of crowns. ${ }^{19}$ In the current study, the mean axial gap for metal crowns was found to be $53.356 \pm 12.916 \mu \mathrm{m}$, which is in agreement with earlier studies. ${ }^{20,21}$ The axial gap of $75.678 \pm 8.996 \mu \mathrm{m}$ for zirconia found in the present study seems to be in agreement with earlier studies of this system. ${ }^{22-24}$

The total mean gap of $27.105 \pm 7.524 \mu \mathrm{m}$ and $65.021 \pm 14.167 \mu \mathrm{m}$ in metal and zirconia frameworks in this study for Cercon crowns seems to be well within the threshold of clinical acceptability, and in accordance with another study which reported that total mean of internal fit in metal ceramic was $30.0 \pm 71.2 \mu \mathrm{m}$ and in zirconia frameworks was $67.7 \pm 114.7 \mu \mathrm{m}^{25}$

Clinical acceptability of marginal fit was 120 $\mu \mathrm{m}$, proposed by McLean and Fraunhofer. ${ }^{26}$ In a recent study, ${ }^{20}$ the marginal gap of Cercon crowns was reported to range from $40-90 \mu \mathrm{m}$, close to the results reported in the current study. The marginal gap values of the present study are also generally comparable to other studies ${ }^{27-9}$ on marginal fit of zirconia crowns, except for one study in which the range was higher $50-160 \mu \mathrm{m} .^{30}$

An increase in thickness of the die spacer layers, resulting in larger internal gap, as in vitro studies have shown. ${ }^{31-32}$ Consequently, an increase in cement thickness caused by a larger internal gap can have a significant effect on the long-term stability of a ceramic reconstruction.$^{33-7}$ In the present study, following the manufacturers instructions, two layers of die spacer were selected for the fabrication of the zirconia frameworks but only one was selected for the metal frameworks. This increased twice the spacer thickness for zirconia group and presumably was part of the reason for the varying adaptation. However, taking the spacer thickness into consideration, zirconia frameworks still tended to exhibit larger gaps in the cervical region in the present study.

Moreover, the replica technique used in the present study to evaluate the internal fit of the restoration has been extensively used as a nondestructive, reliable and valid method. ${ }^{38}$

Randomized controlled clinical long-term studies are needed to obtain further information about the clinical consequences of the varying fit of reconstructions with zirconia and metal frameworks. Updates of the software have been made available and have improved framework fit. Hence, there is a need for more in vitro and in vivo tests with the latest updates to gain further information on the actual status of the adaptation of zirconia and metal frameworks..$^{39-43}$

One shortcoming of this study was the single assessment of measurements by one operator. Future experiments should include repeated measurements, and intra-examiner or inter-examiner agreement should be evaluated.

\section{CONCLUSION}

Within the limitations of this study, we concluded that posterior three-unit FPDs milled zirconia frameworks fabricated according to the manufacturer's specifications exhibited larger internal gaps than those constructed using milled Gold Platinum metal-ceramic technique.

\section{ACKNOWLEDGMENTS}

We wish to thank Prof. Mostafa Abd-El Ghany for his support, Dean of faculty of dentistry AlAzhar university Girls branch, EGYPT. This study funded by first author and Al-Azhar institution. 


\section{REFERENCES}

1- Petteno D, Schierano G, Bassi F, Bresciano ME, Carossa S. Comparison of marginal fit of 3 different metal-ceramic systems: an in vitro study. Int J Prosthodont 2000; 5: 405-8.

2- Rudolph H, Luthardt RG, Walter MH. Computer-aided analysis of the influence of digitizing and surfacing on the accuracy in dental CAD/CAM technology. Comput Biol Med. 2007;37:579-87.

3- Sturzenegger B, Fehe RA, Lu TH, Schumacher M, Loeffel O, Filser F, Kocher P, Gauckler L, Scha RP. Clinical study of zirconium oxide bridges in the posterior segments fabricated with the DCM system. Acta Med Dent Helv 2000; 5: 131-139.

4- Luthardt RG, Holzhu TM, Sandkuhl O, Herold V, Schnapp JD, Kuhlisch E, Walter M. Reliability and properties of ground Y-TZP-zirconia ceramics. J Dent Res 2002; 81: 487-491.

5- Sorensen JA, Kang SK, Torres TJ, Knode H. In-Ceram fixed partial dentures: three-year clinical trial results. J Calif Dent Assoc 1998; 26: 207-214. 4.

6- Vult Von Steyern P, Jonsson O, Nilner K. Five-year evaluation of posterior all-ceramic three-unit (In-Ceram) FPDs. Int J Prosthodont 2001; 14: 379-384.

7- Tinschert J, Natt G, Mautsch W, Spiekermann H, Anusavice K J. Marginal Fit of Alumina- and Zirconia-Based Fixed Partial Dentures Produced by a CAD/CAM System. Oper Dent 2001; 26: 367-374.

8- Farjood E, Vojdani M, Torabi K, Khaledi AA, Marginal and internal fit of metal copings fabricated with rapid prototyping and conventional waxing. J Prosthet 2016;115:136-40.

9- Suttor D, Bunke K, Hoescheler S, Hauptmann H, Hertelein G. Lava - the system for all-ceramic $\mathrm{ZrO} 2$ crown and bridge frameworks. Int J Comput Dent 2001; 4: 195-206.

10- Tinschert J, Natt G, Mautsch W, Spiekermann H, Anusavice KJ. Marginal fit of alumina -and-zirconia fixed partial dentures produced by a CAD/CAM system. Oper Dent. 2001;26:367-74.

11- Shillingburgh HT, Hobo S, Whitsett LD, Jacobi R, Brackett SE. Fundamentals of occlusion, 3rd edn. Chicago: Quintessence, 1997

12- Bindl A, Mo "rmann WH. Fit of all-ceramic posterior fixed partial denture frameworks in vitro. Int J Periodontics Restorative Dent 2007; 27: 567-575
13- Reich S, Wichmann M, Nkenke E, Proeschel P. Clinical fit of all-ceramic three-unit fixed partial dentures, generated with three different CAD/CAM systems. Eur J Oral Sci 2005; 113: 174-179.

14- Fransson B, Øilo G, Gjeitanger R. The fit of metal-ceramic crowns, a clinical study. Dent Mater 1985; 1: 197-199.

15- Holmes RJ, Bayne SC, Holland GA, Sulik WD. Considerations in measurement of marginal fit. J Prosthet Dent 1989; 62: 405-408.

16- Beuer F, Aggstaller H, Edelhoff D, Gernet W, Sorensen J. Marginal and internal fits of fixed dental prostheses zirconia retainers. Dent Mater. 2009;25:94-102

17- Bindl A, Mormann WH. Fit of all-ceramic posterior fixed partial denture frameworks in vitro. Int J Periodontics Restorative Dent. 2007;27:567-575.

18- Att W, Komine F, Gerds T, Strub JR. Marginal adaptation of three different zirconium dioxide three-unit fixed dental prostheses. J Prosthet Dent. 2009;101:239-247.

19- Al Wazzan KA, Al-Nazzawi AA. Marginal and internal adaptation of commercially pure titanium and titaniumaluminum-vanadium alloy cast restorations. J Contemp Dent Pract 2007;8:19-26.

20- Tao J, Han D. The effect of finish line curvature on the marginal fit of all-ceramic CAD/ CAM crowns and metalceramic crowns. Quintessence Int 2009;40:745-52.

21- .Hung SH, Hung KS, Eick JD, Chappell RP. Marginal fit of porcelain-fused-to-metal and two types of ceramic crown. J Prosthet Dent 1990;63:26-31.

22- Yeo IS, Yang JH, Lee JB. In vitro marginal fit of three allceramic crown systems. J Prosthet Dent 2003;90:459-64

23- Sulaiman F, Chai J, Jameson LM, Wozniak WT. A comparison of the marginal fit of InCeram, IPS Empress, and Procera crowns. Int J Prosthodont 1997;10:478-84.

24- Beschnidt SM, Strub JR. Evaluation of the marginal accuracy of different all-ceramic crown systems after simulation in the artificial mouth. J Oral Rehabil 1999;26:582-93.

25- Wettstein F,Sailer I,Roos M, Hammerle CHF.Clinical study of the internal gaps of zirconia and metal frameworks for fixed partial dentures.Eur J Oral Sci 2008;116:272-9.

26- Sailer I, Fehér A, Filser F, Gauckler IJ, Lüthy H, Hämmerle $\mathrm{CH}$. Five-year clinical results of zirconia frameworks for posterior fixed partial dentures. Int J Prosthodont 2007;20:383-8. 
27- Coli P, Karlsson S. Fit of a new pressure sintered zirconium dioxide coping. Int J Prosthodont 2004;17:59-64.

28- Tsirogiannis P, Reissmann DR, Heydecke G. Evaluation of the marginal fit of single-unit, complete-coverage ceramic restorations fabricated after digital and conventional impressions: A systematic review and meta-analysis. J Prosthet Dent. 2016 ;116(3):328-35

29- Okutan M, Heydecke G, Butz F, Strub JR. Fracture load and marginal fit of shrinkage-free $\mathrm{ZiSiO} 4$ all-ceramic crowns after chewing simulation. J Oral Rehabil. 2006;33:827-32.

30- Comlekoglu M, Dundar M, Ozcan M, Gungor M, Gokce B, Artunc C. Influence of cervical finish line type on the marginal adaptation of zirconia ceramic crowns. Oper Dent 2009;34:586-92.

31- Thompson VP, Rekow ED. Dental ceramics and the molar crown testing ground. J Appl Oral Sci 2004;12(Spec. Iss.):26-36.

32- Kim JH, Miranda P, Kim DK, Lawn BR. Effect of an adhesive interlayer on the fracture of a brittle coating on a supporting substrate. J Mater Res 2003; 18: 222-227.

33- DA Silva NRFA, DE Souza GM, Coelho PG, Stappert CFJ, Clark EA, Rekow ED, Thompson VP. Effect of water storage time and composite cement thickness on fatigue of a glass ceramic tri-layer system. J Biomed Mater Res B Appl Biomater 2008; 84: 117-123.

34- Kelly JR, Davis SH, Campbell SD. Nondestructive, three dimensional internal fit mapping of fixed prostheses. J Prosthet Dent. 1989;61:368-73.

35- Zeltner M, Sailer I, Mühlemann S, Özcan M, Hämmerle HF, Benic GI, Randomized controlled within-subject evaluation of digital and conventional workflows for the fabrication of lithium disilicate single crowns. Part III: marginal and internal fit.J Prosthet Dent.2016;116(4)412-20.
36- Pimenta MA, LC, Lopes R Rivaldo E, Evaluation of marginal and internal fit of ceramic and metallic crown copings using $\mathrm{x}$-ray microtomography (micro-CT) technology. J Prosthet Dent 2015 ;114, (2) 223-8

37- Fathi HM, Al-Masoody AH, El-Ghezawi N, Johnson A, The Accuracy of Fit of Crowns Made From Wax Patterns Produced Conventionally (Hand Formed) and Via CAD/ CAM Technology. Eur J Prosthodont Restor Dent. 2016 ; 24(1):10-7.

38- Johnson R, Verrett R, Haney S, Mansueto M, Challa S. Marginal Gap of Milled versus Cast Gold Restorations. J Prosthodont. 2016 ;34(4):46-52

39- Reyes, A., Turkyilmaz, I., Prihoda, T.J. Accuracy of surgical guides made from conventional and a combination of digital scanning and rapid prototyping techniques. J Prosthet Dent. 2015;113:295-303.

40- Baig, M.R., Tan, K.B., Nicholls, J.I. Evaluation of the marginal fit of a zirconia ceramic computer-aided machined (CAM) crown system. J Prosthet Dent. 2010;104:216-227.

41- Vojdani, M., Torabi, K., Farjood, E., Khaledi, A.A.R. Comparison the marginal and internal fit of metal copings cast from wax patterns fabricated by CAD/CAM and conventional wax up techniques. J Dent (Shiraz). 2013;14:118-129.

42- Han, H.S., Yang, H.S., Lim, H.P., Park, Y.J. Marginal accuracy and internal fit of machine milled and cast titanium crowns. J Prosthet Dent. 2011;106:191-197.

43- Benic GI, Mühlemann S, Fehmer V, Hämmerle CHF, Sailer Randomized controlled within-subject evaluation of digital and conventional workflows for the fabrication of lithium disilicate single crowns. Part I: digital versus conventional unilateral impressions.J Prosthet Dent. 2016;116(5):777-782 